\title{
SPECTROPHOTOMETRIC METHODS FOR DETERMINATION OF SOFOSBUVIR AND DACLATASVIR IN PURE AND DOSAGE FORMS
}

\author{
MONIR Z. SAAD, ATEF AMER, KHALED ELGENDY, BASEM ELGENDY* \\ Chemistry Department, Faculty of Science, Zagazig University, Zagazig, 44519, Egypt \\ Email: beso_elgendy@yahoo.com
}

Received: 28 Jun 2021, Revised and Accepted: 09 Aug 2021

\section{ABSTRACT}

Objective: Two simple, sensitive and accurate spectrophotometric methods have been developed for the determination of sofosbuvir (SOF) and daclatasvir (DAC) in pure forms and pharmaceutical formulations.

Methods: The proposed methods are based on the oxidation of SOF and DAC by a known excess of cerium(IV) ammonium nitrate in sulphuric acid medium followed by determination of unreacted cerium(IV) by adding a fixed amount of indigo carmine (IC) and alizarin red S (ARS) dyes followed by measuring the absorbance at 610 and $360 \mathrm{~nm}$, respectively. The experimental conditions affecting the reaction were studied and optimized.

Results: The beer's law was obeyed in the concentration ranges of 0.2-3.0, 0.2-4.0 for SOF and 0.5-4.5 and 0.5-5.0 $\mu \mathrm{g} / \mathrm{ml}$ for DAC using IC and ARS methods, respectively with a correlation coefficient 0.9991 . The calculated molar absorptivity value s are $2.354 \times 10^{4}, 1.933 \times 10^{4}$ for SOF and $1.786 \times 10^{4}$ and $2.015 \times 10^{4} \mathrm{~L} / \mathrm{mol}$. cm for DAC using IC and ARS methods, respectively u. The limits of detection and quantification are also reported. Intra-day and inter-day precision and accuracy of the methods have been evaluated.

Conclusion: The methods were successfully applied to the assay of SOF and DAC in tablets and the results were statistically compared with those of the reference method by applying Student's $t$-test and $F$-test. No interference was observed from the common tablet excipients. The accuracy and reliability of the methods were further ascertained by performing recovery studies using the standard addition method.

Keywords: Sofosbuvir, Daclatasvir, Spectrophotometry, Cerium (IV), Dyes, Method validation, Dosage forms

(C) 2021 The Authors. Published by Innovare Academic Sciences Pvt Ltd. This is an open access article under the CC BY license (https://creativecommons.org/licenses/by/4.0/) DOI: https://dx.doi.org/10.22159/ijap.2021v13i6.42564. Journal homepage: https://innovareacademics.in/journals/index.php/ijap

\section{INTRODUCTION}

Sofosbuvir, (S)-Isopropyl 2-((S)-(((2R,3R,4R,5R)-5-(2,4-dioxo-3,4dihydropyrimidin 1(2H)-yl)-4-fluoro-3-hydroxy-4-methyltetrahydrofuran-2-yl)methoxy) (phenoxy) phosphorylamino) propanoate (SOF) (fig. 1). It is a prodrug nucleotide analog used for the treatment of chronic hepatitis $C$, genotypes $1,2,3,4,5$, and 6 , usually in combination with other medications depending on the specific genotype. Sofosbuvir, is a medication used in combination with other medications for the treatment of hepatitis $C[1,2]$.

Daclatasvir dihydrochloride (DAC) is methyl [(2S)-1-\{(2S)-2-[4-(4$\{2-[(2 S)-1-\{(2 S)-2-[($ methoxy carbonyl)amino]-3-methyl butanoyl $\}-$

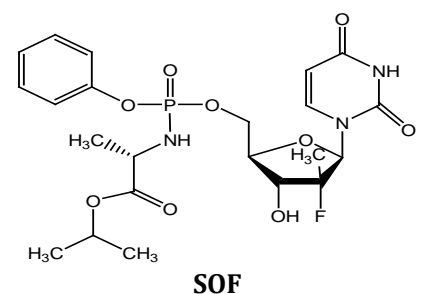

2-pyrrolidinyl]-1H-imidazol-4-yl\}-4-biphenyl yl)-1H-imidazol-2-yl]1-pyrrolidinyl\}-3-methyl-1-oxo-2-butanyl] carbamate dihydrochloride (fig. 1). DAC is an antiviral drug used to treat chronic (long-lasting) hepatitis $\mathrm{C}$, a viral infection of the liver. DAC is an antiviral and acts directly against the hepatitis $\mathrm{C}$ virus [3].

Literature survey reveals that there is few methods have been reported for the assay of SOF and DAC in pharmaceutical dosage forms, including High-Performance Liquid Chromatography (HPLC) [4-12], upper high-performance chromatography (UHPC) [13-17] and electrochemical method [18]. These methods are complex, require long and tedious pre-treatment of the samples and laborious clean up procedures prior to analysis.

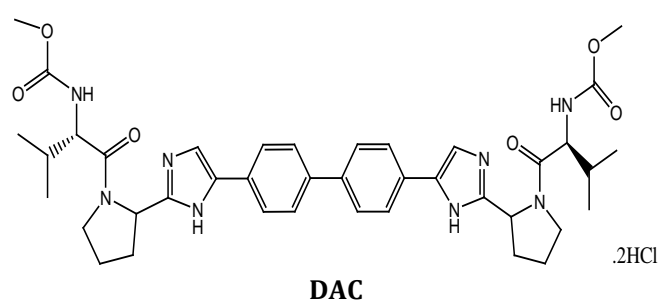

Fig. 1: Chemical structures of sofosbuvir (SOF) and daclatasvir dihydrochloride (DAC)

A through literature search has revealed that only a few spectrophotometric methods have been developed for the determination of SOF and DAC in pure and dosage forms [19-26]. However, many of the above methods suffered from one or other disadvantage like poor sensitivity, require high cost solvents in addition to elaborate treatment, need tedious extraction procedures, rigid $\mathrm{pH}$ control, measurements done at shorter wavelengths, heating or cooling step, use of expensive chemical and/or complicated experimental set-up. In contrast, visible spectrophotometry is considered as the most convenient analytical technique in most quality control and clinical laboratories. Spectrophotometric technique, because of simplicity and low cost, sensitivity and good analytical selectivity, significant accuracy and precision and broad availability and applicability for pharmaceutical analysis.

Cerium(IV) has been widely used as an effective analytical reagent in spectrophotometric methods for the determination of many pharmaceutical compounds [27-35]. Cerium(IV) is a strong oxidant, and it has not been applied for the assay of SOF and DAC in pure forms and tablets.

This paper describes for the first time the application of acidic ammonium cerium(IV) nitrate to the spectrophotometric determination 
of SOF and DAC using Indigo Carmine (IC) and Alizarin Red S (ARS) as chromogenic agents. The proposed methods have the advantages of simplicity, sensitivity and rapidity besides being accurate precise and validated spectrophotometric method for the estimation of SOF and DAC in pure and dosage forms and can be adopted by the pharmaceutical laboratories for industrial quality control.

\section{MATERIALS AND METHODS}

\section{Apparatus}

All absorption spectra were made using Shimadzu UV/Vis, double beam spectrophotometer (Japan) equipped with a $10 \mathrm{~mm}$ quartz cell was used for absorbance measurements.

\section{Materials and reagents}

All chemicals and reagents used were of analytical or pharmaceutical grade and all solutions were prepared fresh daily. Bidistilled water was used throughout the investigation.

\section{Pure drugs and pharmaceutical formulations}

Pharmaceutical grade SOF was kindly supplied by SEDICO, Cairo, Egypt. The commercial pharmaceutical formulations (Hopforhep labeled to contain $400 \mathrm{mg}$ SOF per tablet and Daclahepex tablets labeled to contain $60 \mathrm{mg}$ DAC per tablet) (Global Napi Pharmaceutical Company, Egypt), were purchased from local market were subjected to the analytical procedure.

\section{Stock standard solution}

A standard stock solutions of SOF or DAC containing $100 \mu \mathrm{g} / \mathrm{ml}$ and $\left(1 \times 10^{-3} \mathrm{~mol} / \mathrm{l}\right)$ were prepared by dissolving the appropriate weight of pure drug in $20 \mathrm{ml}$ bidistilled water and was further diluted to $100 \mathrm{ml}$ to obtain the working concentration. The standard solution was kept in the refrigerator and was found to be stable for at least one week if they had been stored in a $\operatorname{cool}\left(<25^{\circ} \mathrm{C}\right)$ and dark place.

\section{Reagents}

A stock solution of $1.0 \times 10^{-3} \mathrm{~mol} / \mathrm{l}$ ammonium cerium(IV) nitrate (Sigma-aldrish, USA) was freshly prepared by dissolving $54.8 \mathrm{mg}$ of ammonium cerium(IV) nitrate in the least amount of $\mathrm{H}_{2} \mathrm{SO}_{4}(2.0$ $\mathrm{mol} / \mathrm{l}$ ) then completed to the mark in a $100 \mathrm{ml}$ calibrated flask with the same acid and kept in a dark bottle and a refrigerator when not in use. A stock solution of $2.0 \mathrm{~mol} / \mathrm{l} \mathrm{H}_{2} \mathrm{SO}_{4}$ was prepared by adding $10.8 \mathrm{ml}$ of concentrated acid (Merck, Darmstadt, Germany, 98\%, Sp. Gr. 1.84) to bidistilled water, cooled to room temperature, transfer to $100 \mathrm{ml}$ with measuring flask, diluted to the mark and standardized as recorded [36].

A stock solutions $\left(1.0 \times 10^{-3} \mathrm{~mol} / \mathrm{l}\right)$ IC and ARS (Sigma-aldrish, USA) were first prepared by dissolving accurately weighed $46 \mathrm{mg}$ and 24 $\mathrm{mg}$ of IC and ARS, respectively in bidistilled water and diluting to volume in a $100 \mathrm{ml}$ calibrated flask.

\section{General procedures}

Different aliquots containing $(0.2--4.0 \mu \mathrm{g} / \mathrm{ml})$ SOF and (0.5-5.0 $\mu \mathrm{g} / \mathrm{ml}$ ) DAC solution were transferred into a series of $10 \mathrm{ml}$

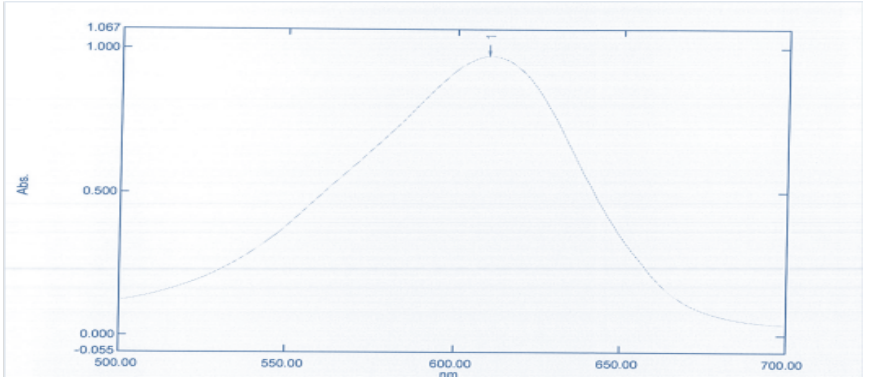

(a) calibrated flasks by means of a micro pipette and the total volume was adjusted to $5.0 \mathrm{ml}$ by adding adequate quantity of water. To each flask $2.0 \mathrm{ml}$ of $\left(1.0 \times 10^{-3} \mathrm{~mol} / \mathrm{l}\right)$ ammonium cerium (IV) nitrate solution was added and waiting for $15 \mathrm{~min}$. at $50{ }^{\circ} \mathrm{C}$, then add $2.0 \mathrm{ml}$ of $2.0 \mathrm{~mol} / \mathrm{l} \mathrm{H}_{2} \mathrm{SO}_{4}$. The flasks were stoppered, contents were mixed well with occasional shaking. Finally, 0.5 and $1.0 \mathrm{ml}$ of IC and ARS dye solution were added, respectivelt to each flask and mixed well, and then the volume was diluted to the mark with bidistilled water. The color intensity of dyes was measured after 5.0 min against reagent blank solution treated similarly omitting the drug, at their corresponding $\lambda_{\max } 610$, and $360 \mathrm{~nm}$ for IC and ARS dye, respectively. The concentration of unknown was determined in each case from calibration graph or computed from the regression equation derived using Beer's law data.

\section{Assay procedure for pharmaceutical formulations}

The content of ten tablets each containing $10 \mathrm{mg}$ SOF or DAC was finely powdered using an agate mortar and weighed accurately. An accurately weighed quantity of the powder equivalent to $10 \mathrm{mg}$ SOF or DAC were transferred into $100 \mathrm{ml}$ calibrated flask and dissolved in $25 \mathrm{ml}$ methanol. The content of the flask was shaken and sonicated for about $10 \mathrm{~min}$, mixed well and then filtered using Whatman No.42 filter paper. The first portion of the filtrate was rejected, and the solution was then completed to volume with bidistilled water to prepare a stock solution of $100 \mu \mathrm{g} / \mathrm{ml}$. Aliquots covering the working concentration ranges for each method were transferred into a series of $10 \mathrm{ml}$ volumetric flasks and the proposed methods were applied. The nominal content of the tablets was determined using the corresponding regression equations or the calibration graphs.

\section{RESULTS AND DISCUSSION}

\section{Absorption spectra}

The proposed spectrophotometric methods for the determination of SOF or DAC is indirect and involves two steps namely:

1. Oxidation of SOF or DAC with a known excess of cerium(IV) in acidic medium.

2. Determination of the residual cerium(IV) by reacting it with a fixed amount of IC or ARS dyes and measuring the increase in absorbance at $\lambda_{\max } 610$ and $360 \mathrm{~nm}$, respectively (Scheme 1) (fig. 2a and 2b).

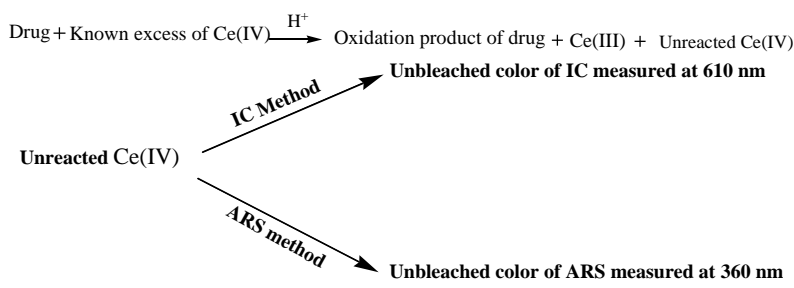

Scheme 1: The suggested reaction pathway for the proposed spectrophotometric methods using cerium(IV) and dyes

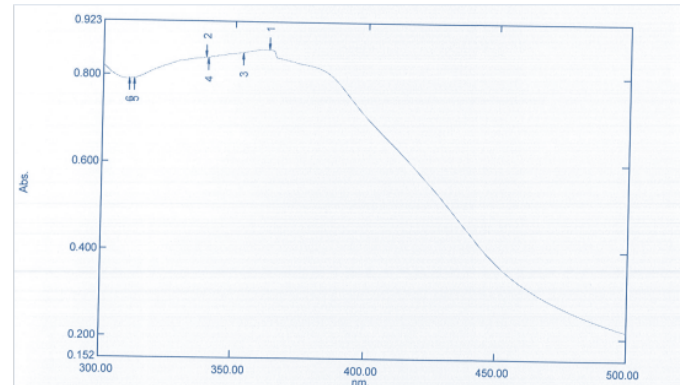

(b)

Fig. 2: Absorption spectra for the unreacted cerium(IV) oxidant that determined by reacting with a fixed amount of (a) IC and (b) ARS dyes and measuring the absorbance at 610 and $360 \mathrm{~nm}$ for IC and ARS methods, respectively 


\section{Optimization of the reaction conditions}

The optimum conditions for the assay procedures and color development for each method have been established by varying the parameters one at a time, keeping the others fixed and observing the effect produced on the absorbance of the colored species.

\section{Effect of cerium(IV) sulphate concentration}

The influence of the concentration of cerium(IV) ammonium nitrate on the absorbance of the colored products was investigated using different volumes of $1.0 \times 10^{-3} \mathrm{~mol} / \mathrm{l}$ cerium(IV) solution from $(0.25$ $4.0 \mathrm{ml})$. The results indicate that the maximum and constant absorbance was obtained using $2.0 \mathrm{ml}$ of $1.0 \times 10^{-3} \mathrm{~mol} /$ lcerium(IV) solution for both drugs (SOF and DAC) and the color intensity constant or decreased (fig. 3a and 3b).

\section{Effect of dye concentration}

The effect of IC or ARS dye concentration on the intensity of the color developed was carried out to obtain the optimum concentration of dyes that produces the maximum and reproducible color intensity by reducing the residual of cerium (IV). The effect dye concentration was studied using different volumes $(0.25-2.0 \mathrm{ml})$ of the studied dyes $\left(1.0 \times 10^{-3} \mathrm{~mol} / \mathrm{l}\right)$ (fig. $4 \mathrm{a}$ and $\left.4 \mathrm{~b}\right)$. It was observed that maximum color intensity of the oxidation products was achieved with 0.5 and $1.0 \mathrm{ml}$ of IC and ARS dye solution, respectively. The color was found to be stable up to $10 \mathrm{~h}$.
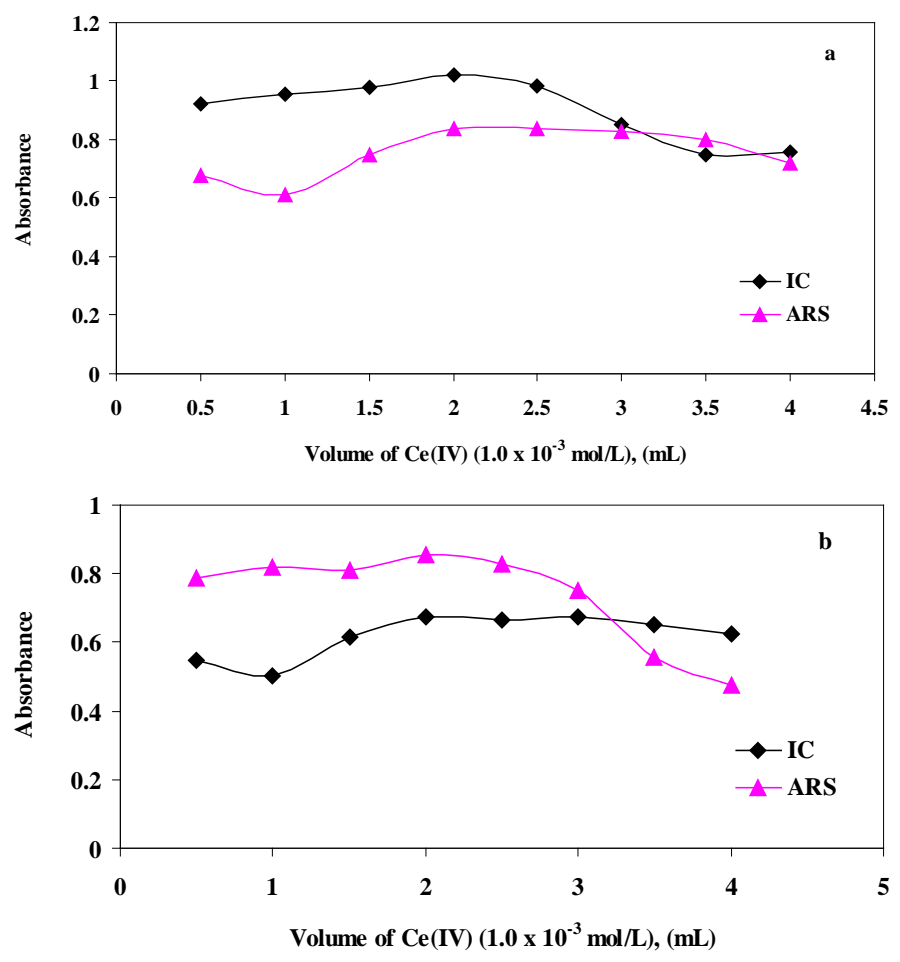

Fig. 3: Effect of volume of cerium (IV) $\left(1.0 \times 10^{-3} \mathrm{~mol} / \mathrm{l}\right)$ on the reaction product of (a) SOF and (b) DAC and dyes in $\mathrm{H}_{2} \mathrm{SO}_{4}$ medium
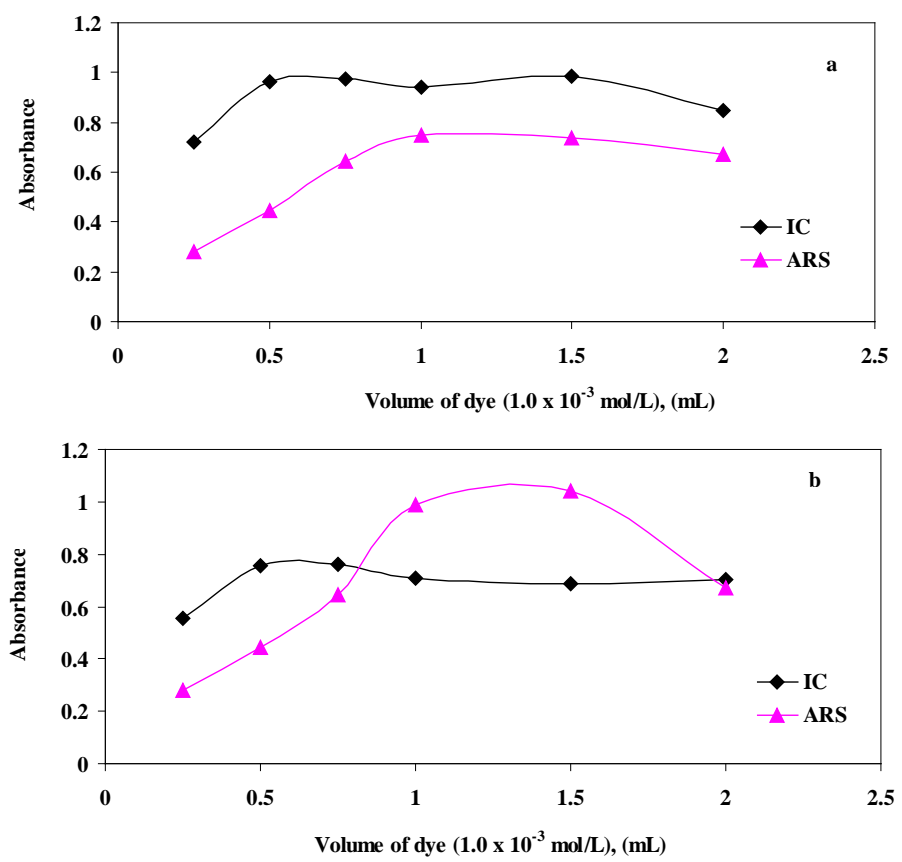

Fig. 4: Effect of volume of dye $\left(1.0 \times 10^{-3} \mathrm{~mol} / \mathrm{l}\right)$ on the reaction product of (a) SOF and (b) DAC with Ce(IV) in $\mathrm{H}_{2} \mathrm{SO}_{4}$ medium 


\section{Effect of acid type and concentration}

Different types of acids were examined $\left(\mathrm{HCl}, \mathrm{H}_{2} \mathrm{SO}_{4}, \mathrm{H}_{3} \mathrm{PO}_{4}, \mathrm{HNO}_{3}\right.$ and $\mathrm{CH}_{3} \mathrm{COOH}$ ) to achieve maximum yield of redox reactions. The results indicated that the sulphuric acid $\left(\mathrm{H}_{2} \mathrm{SO}_{4}\right)(2.0 \mathrm{~mol} / \mathrm{l})$ was the most suitable acid with cerium (IV) as oxidant. Moreover, different volumes $(0.25-3.0 \mathrm{ml})$ of $2.0 \mathrm{~mol} / \mathrm{l} \mathrm{H}_{2} \mathrm{SO}_{4}$ were tested, keeping the concentrations of oxidant and drug fixed. The results indicated that, at (1.5-2.5 ml) of $\mathrm{H}_{2} \mathrm{SO}_{4}(2.0 \mathrm{~mol} / \mathrm{l})$, there were almost same absorbance values were obtained in the presence of the studied drugs. At the acid volumes less than $1.5 \mathrm{ml}$, reaction led to go slower and incomplete. Therefore, $2.0 \mathrm{ml}$ of $\mathrm{H}_{2} \mathrm{SO}_{4}(2.0 \mathrm{~mol} / \mathrm{l})$ was the optimum volume for subsequent studies (fig. 5).

\section{Effect of temperature and mixing time}

The effect of temperature was studied by heating a series of sample and blank solutions at different temperatures ranging from 25 to 80 ${ }^{\circ} \mathrm{C}$ in water bath. It was found that raising the temperature does not accelerate the oxidation process and does not give reproducible results, so maximum color intensity was obtained at temperature $\left(50{ }^{\circ} \mathrm{C}\right)$. The effect of mixing time required completing oxidation of SOF or DAC and for reducing the excess oxidant was studied by measuring the absorbance of sample solution against blank solution prepared similarly at various time intervals $2.0-30 \mathrm{~min}$. It was found that the contact times gave constant and reproducible absorbance values at $15.0 \mathrm{~min}$. After oxidation process, $5.0 \mathrm{~min}$ standing time was found necessary for the complete bleaching of the dye color by the residual cerium (IV) and the absorbance of the unreacted dye was stable for at least $10 \mathrm{~h}$, thereafter (fig. 6).

\section{Effect of sequence of addition}

After optimizing all other experimental variables, further experiments were performed to ascertain the influence of sequence of addition of reactants on the color development by measuring the absorbance. The optimum sequence of addition for both drugs was (drug-cerium (IV) ammonium nitrate- $\mathrm{H}_{2} \mathrm{SO}_{4}$-dye). Other sequences gave lower absorbance values under the same experimental conditions.

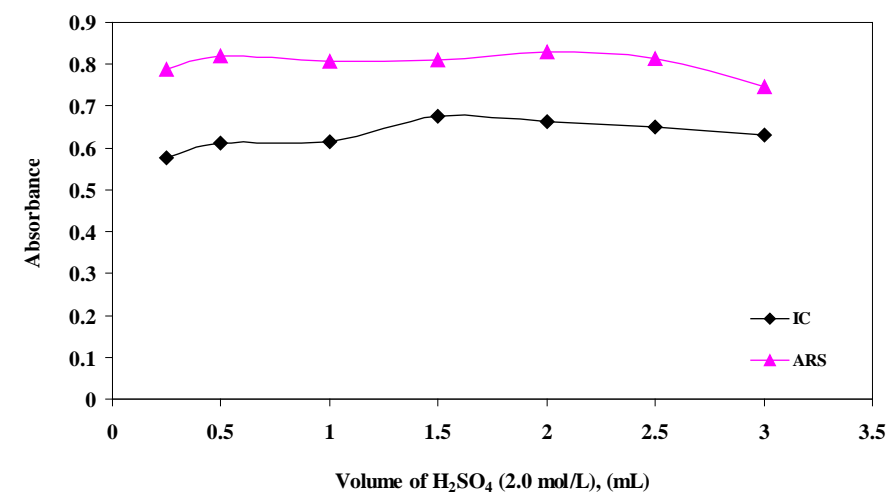

Fig. 5: Effect of volume of $\mathrm{H}_{2} \mathrm{SO}_{4}(2.0 \mathrm{~mol} / \mathrm{l})$ on the absorbance of SOF with cerium (IV) $\left(1.0 \times 10^{-3} \mathrm{~mol} / \mathrm{l}\right)$ and $\left(1.0 \times 10^{-3} \mathrm{~mol} / \mathrm{l}\right) \mathrm{dye}$

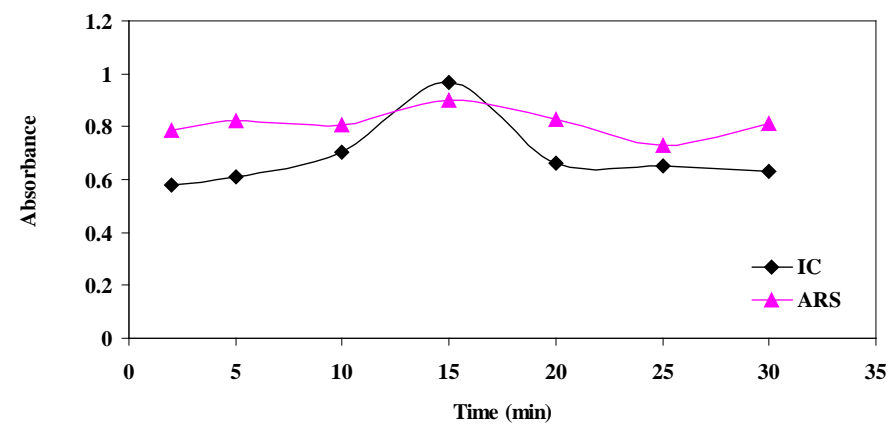

Fig. 6: Effect of time on the absorbance of the reaction product: (SOF with cerium (IV) $\left(1.0 \times 10^{-3} \mathrm{~mol} / \mathrm{l}\right)$ and dyes $\left(1.0 \times 10^{-3} \mathrm{~mol}_{/} / \mathrm{l}\right)$ in $\mathrm{H}_{2} \mathrm{SO}_{4}$ acidic medium)

\section{Validation of the proposed methods}

The validity of the methods was tested regarding linearity, specificity, accuracy, repeatability and precision according to International Conference on Harmonization (ICH) [37] guidelines.

\section{Linearity, detection, and quantification limits}

Following the proposed experimental conditions, linear regression equations were obtained. The regression plots showed that there was a linear dependence of the absorbance to the concentration in the range of 0.2-3.0, 0.2-4.0 for SOF and 0.5-4.5 and $0.5-5.0 \mu \mathrm{g} / \mathrm{ml}$ for DAC using IC and ARS methods, respectively. Linear regression analysis of the data gave the following equations $A=$ $0.0342+0.3063 \mathrm{C}, \mathrm{r}^{2}=0.9991$ and $\mathrm{A}=0.0799+0.0 .2134 \mathrm{C}, \mathrm{r}^{2}=0.9996$ for SOF using IC and ARS, respectively. While for DAC, $A=$ $0.0198+0.1413 \mathrm{C}, \mathrm{r}^{2}=0.9991$ and $\mathrm{A}=-0.0224+0.1694 \mathrm{C}, \mathrm{r}^{2}=0.9991$ using IC and ARS, respectively, where $A$ is the absorbance, $C$ is the concentration of drug, and $\mathrm{r}^{2}$ is the correlation coefficient.
The limits of detection (LOD) were determined by establishing the minimum level at which the analyte can be reliably detected, and the limit of quantification (LOQ) was determined by establishing the lowest concentration that can be measured with acceptable accuracy and precision according to ICH $[37,38]$. The results are also summarized in table 1. LOQ and LOD were calculated according to the following equations (Eqn. 1. and Eqn. 2):

$$
\begin{gathered}
\mathrm{LOD}=3 s / k \ldots . \text { Eqn. } 1 . \\
\mathrm{LOQ}=10 \mathrm{~s} / \mathrm{k} \ldots . . \text { Eqn. } 2 .
\end{gathered}
$$

Where $s$ is the standard deviation of ten replicate determinations values of the reagent blank and $\mathrm{k}$ is the sensitivity, namely the slope of the calibration graph. In accordance with the formula, for SOF and DAC the LOD were found to be 0.06 and $0.15 \mu \mathrm{g} / \mathrm{ml}$ and LOQ were found to be 0.20 and $0.50 \mu \mathrm{g} / \mathrm{ml}$ sing IC and ARS, respectively. 
Table 1: Analytical and regression parameters of proposed oxidation spectrophotometric methods for determination of SOF and DAC

\begin{tabular}{|c|c|c|c|c|}
\hline \multirow[t]{2}{*}{ Parameters } & \multicolumn{2}{|l|}{ SOF } & \multicolumn{2}{|l|}{ DAC } \\
\hline & IC & ARS & IC & ARS \\
\hline Wavelength (nm) & 610 & 360 & 610 & 360 \\
\hline Beer's law limits, $\mu \mathrm{g} / \mathrm{ml}$ & $0.2-3.0$ & $0.2-4.0$ & $0.5-4.5$ & $0.5-5.0$ \\
\hline Molar absorptivity, x $10^{4} \mathrm{l} / \mathrm{mol} . \mathrm{cm}$ & 2.354 & 1.933 & 1.786 & 2.015 \\
\hline Sandell sensitivity, $\mathrm{ng} \mathrm{cm}^{-2}$ & 22.47 & 27.37 & 45.45 & 40.29 \\
\hline \multicolumn{5}{|l|}{ Regression equation ${ }^{a}$} \\
\hline Intercept (a) & 0.0342 & 0.0799 & -0.0198 & -0.0224 \\
\hline Standard deviation of intercept $\left(\mathrm{S}_{\mathrm{a}}\right)$ & 0.084 & 0.075 & 0.091 & 0.11 \\
\hline Slope (b) & 0.3063 & 0.2134 & 0.1413 & 0.1694 \\
\hline Standard deviation of slope $\left(\mathrm{S}_{\mathrm{b}}\right)$ & 0.09 & 0.12 & 0.089 & 0.086 \\
\hline Correlation coefficient, (r) & 0.9991 & 0.9996 & 0.9991 & 0.9991 \\
\hline mean \pm SD & $99.20 \pm 0.60$ & $99.40 \pm 0.80$ & $99.80 \pm 0.90$ & $99.50 \pm 0.70$ \\
\hline $\mathrm{RSD} \%$ & 0.60 & 0.80 & 0.90 & 0.70 \\
\hline $\mathrm{RE} \%$ & 0.63 & 0.84 & 0.94 & 0.73 \\
\hline Limit of detection, $\mu \mathrm{g} / \mathrm{ml}$ & 0.06 & 0.06 & 0.15 & 0.15 \\
\hline Limit of quantification, $\mu \mathrm{g} / \mathrm{ml}$ & 0.20 & 0.20 & 0.50 & 0.50 \\
\hline Calculated $t$-value & 1.64 & 0.85 & 0.43 & 0.26 \\
\hline Calculated $F$-value b & 1.33 & 0.91 & 3.0 & 1.81 \\
\hline
\end{tabular}

${ }^{\text {a }} A=a+b C$, where $C$ is the concentration in $\mu \mathrm{g} / \mathrm{ml}, A$ is the absorbance units, $a$ is the intercept, $b$ is the slope., bThe theoretical values of $t$ and $F$ are 2.57 and 5.05, respectively at confidence limit at $95 \%$ confidence level and five degrees of freedom $(p=0.05)$.

\section{Accuracy and precision}

To evaluate the accuracy and precision of the proposed methods, intraday and inter-day determination of SOD and DAC at three different concentrations for each method were prepared and analyzed. The intraday studies were performed in one day and interday studies in five days (for each level $n=6$ ). The percentage relative error (RE\%) was calculated using the following equation:

$$
\mathbf{R E} \%=\frac{(\text { Found }- \text { Added })}{\text { Added }} \times 100
$$

The accuracy and precisions expressed as percent relative error (RE\%) and relative standard deviation (RSD\%) values, respectively and found to be within-1.50-0.50\% and $1.01-2.51 \%$, respectively for SOF and found to be within-1.10-0.40\% and $1.0-2.52 \%$, respectively for DAC for intra-day analysis and within-1.0-0.60\% and 1.35$2.94 \%$, respectively for SOF and found to be within-1.0-0.30\% and $1.0-2.03 \%$, respectively for DAC for inter-day analysis (table 2). The data proved good accuracy and precision for the developed methods.

Table 2: Results of intra-day and inter-day accuracy and precision study obtained by the proposed methods

\begin{tabular}{|c|c|c|c|c|c|c|c|c|c|}
\hline Method & $\begin{array}{l}\text { Taken } \\
(\mu \mathrm{g} / \mathrm{ml})\end{array}$ & $\begin{array}{l}\text { Recovery } \\
\%\end{array}$ & $\begin{array}{l}\text { Precision } \\
\text { RSD \% }{ }^{\mathrm{a}}\end{array}$ & $\begin{array}{l}\text { Accuracy } \\
\text { RE \% }\end{array}$ & $\begin{array}{l}\text { Confidence } \\
\text { limitb }^{b}\end{array}$ & $\begin{array}{l}\text { Recovery } \\
\%\end{array}$ & $\begin{array}{l}\text { Precision } \\
\text { RSD \%a } \\
\end{array}$ & $\begin{array}{l}\text { Accuracy } \\
\text { RE \% }\end{array}$ & $\begin{array}{l}\text { Confidence } \\
\text { limit }^{b}\end{array}$ \\
\hline & & SOF & & & & DAC & & & \\
\hline & Intra-day & & & & & & & & \\
\hline \multirow[t]{3}{*}{ IC } & 1.0 & 99.00 & 2.0 & -1.0 & $0.99 \pm 0.02$ & 99.40 & 1.01 & -0.60 & $0.994 \pm 0.01$ \\
\hline & 2.0 & 99.60 & 2.51 & -0.40 & $1.992 \pm 0.05$ & 99.00 & 2.02 & -1.0 & $1.980 \pm 0.04$ \\
\hline & 3.0 & 100.50 & 1.99 & 0.50 & $3.015 \pm 0.06$ & 99.70 & 1.0 & -0.30 & $2.991 \pm 0.03$ \\
\hline \multirow[t]{4}{*}{ ARS } & 1.0 & 99.20 & 1.01 & -0.80 & $0.992 \pm 0.01$ & 98.90 & 2.02 & -1.10 & $0.989 \pm 0.02$ \\
\hline & 2.0 & 99.70 & 1.50 & -0.30 & $1.994 \pm 0.03$ & 99.10 & 2.52 & -0.90 & $1.982 \pm 0.05$ \\
\hline & 3.0 & 98.50 & 1.69 & -1.50 & $2.955 \pm 0.05$ & 100.40 & 2.32 & 0.40 & $3.012 \pm 0.07$ \\
\hline & Inter-day & & & & & & & & \\
\hline \multirow[t]{3}{*}{ IC } & 1.0 & 100.20 & 2.94 & 0.20 & $1.02 \pm 0.03$ & 99.50 & 1.05 & -0.50 & $0.995 \pm 0.01$ \\
\hline & 2.0 & 100.60 & 1.99 & 0.60 & $2.012 \pm 0.04$ & 99.10 & 1.51 & -0.90 & $1.982 \pm 0.03$ \\
\hline & 3.0 & 99.30 & 1.68 & -0.70 & $2.979 \pm 0.05$ & 99.00 & 1.35 & -1.0 & $2.970 \pm 0.04$ \\
\hline \multirow[t]{3}{*}{ ARS } & 1.0 & 99.80 & 2.0 & -0.20 & $0.998 \pm 0.02$ & 100.30 & 1.0 & 0.30 & $1.003 \pm 0.01$ \\
\hline & 2.0 & 100.20 & 2.50 & 0.20 & $2.004 \pm 0.05$ & 99.40 & 2.01 & -0.60 & $1.988 \pm 0.04$ \\
\hline & 3.0 & 99.00 & 1.35 & -1.0 & $2.970 \pm 0.04$ & 98.70 & 2.03 & -1.30 & $2.961 \pm 0.06$ \\
\hline
\end{tabular}

${ }^{a} \mathrm{RSD} \%$, percentage relative standard deviation; RE\%, percentage relative error. ${ }^{\mathrm{b}} \mathrm{mean} \pm$ standard error.

\section{Ruggedness and robustness}

Robustness of the proposed method was assessed by evaluating the influence of small variation of experimental variables, including concentration of analytical reagents and reaction time, on the analytical performance of the proposed method. In these experiments, one experimental parameter was changed while the other parameters were kept unchanged, and the recovery percentage was calculated each time. The analysis was performed with altered conditions by taking three different concentrations of SOF or DAC and it was found that the small variations in any of the variables did not significantly affect the results. The RSD\% values were in the ranges $0.60-2.10 \%$ and $0.40-1.50$ for SOF and DAC, respectively (table 3 ). This indicated the reliability of the proposed method during its routine application for the analysis of SOF or DAC. The ruggedness of the proposed method was assessed by applying the procedures using two different instruments in three different laboratories (instruments) at different times and three different analysts. The inter-analysts RSD\% were in the ranges $0.56-1.90 \%$ and $0.58-1.90 \%$ for SOF and DAC, respectively, whereas the inter-instruments RSD\% ranged from $0.56-1.80 \%$ and $0.60-2.20 \%$ for SOF and DAC, respectively, these results were found to be reproducible because the RSD did not exceed $3.0 \%$ (table 3). 
Table 3: Results of method robustness and ruggedness (all values in RSD \%) studies

\begin{tabular}{|c|c|c|c|c|c|}
\hline \multirow[t]{4}{*}{ Methods } & \multirow{4}{*}{$\begin{array}{l}\text { Nominal amount } \\
\text { concentration } \\
(\mu \mathrm{g} / \mathrm{ml})\end{array}$} & \multicolumn{4}{|l|}{ RSD\% } \\
\hline & & Robustness & & Ruggedness & \\
\hline & & \multicolumn{4}{|l|}{ Variable alerted a } \\
\hline & & Acid volume $(n=3)$ & Reaction time $(n=3)$ & Different analysts $(n=3)$ & Different instruments $(n=3)$ \\
\hline & & SOF & & & \\
\hline \multirow[t]{3}{*}{ IC } & 1.0 & 0.65 & 0.75 & 0.56 & 0.80 \\
\hline & 2.0 & 1.0 & 1.20 & 0.90 & 1.40 \\
\hline & 3.0 & 1.70 & 2.10 & 1.90 & 1.80 \\
\hline \multirow[t]{4}{*}{ ARS } & 1.0 & 0.80 & 0.60 & 0.73 & 0.56 \\
\hline & 2.0 & 0.920 & 1.30 & 1.0 & 0.87 \\
\hline & 3.0 & 1.20 & 0.90 & 1.10 & 1.40 \\
\hline & & DAC & & & \\
\hline \multirow{3}{*}{ IC } & 1.0 & 0.40 & 0.70 & 0.58 & 1.18 \\
\hline & 2.0 & 0.90 & 0.87 & 0.80 & 0.60 \\
\hline & 3.0 & 1.30 & 1.50 & 1.20 & 2.20 \\
\hline \multirow[t]{3}{*}{ ARS } & 1.0 & 0.76 & 0.48 & 1.18 & 0.85 \\
\hline & 2.0 & 0.95 & 0.86 & 1.45 & 1.16 \\
\hline & 3.0 & 1.32 & 1.58 & 1.90 & 2.10 \\
\hline
\end{tabular}

aVolume of $(2.0 \mathrm{~mol} / \mathrm{l}) \mathrm{H}_{2} \mathrm{SO}_{4}$ is $( \pm 0.2 \mathrm{ml})$ and reaction time is $( \pm 2.0 \mathrm{~min})$ (after adding cerium (IV)) were used.

\section{Effect of interferences and recovery studies}

The specificity of the proposed method was investigated by observing any interference encountered from the common tablets excipients such as starch, talk, chloride, $\mathrm{MgSO}_{4}$ and cellulous by 20 fold excess with $1 \times 10^{-2}$ concentration of each drug was added and the absorbance values showed that there is no interference with each one. Also, the standard addition method was applied by adding known amounts of pure SOF or DAC to a previously analyzed tablet solution. This study was performed by spiking three different levels of pure SOF or DAC $(50,100$ and $150 \%$ of the level present in the tablet) to a fixed amount of drugs in tablet powder (pre-analysed) and the total concentration was found by the proposed methods.
The determination with each level was repeated three times and the percent recovery of the added standard was calculated from Eqn. 3:

$$
\% \text { Recovery }=\frac{\left[C_{F}-C_{T}\right]}{C_{p}} \times 100 \ldots \text { Eqn. } 5
$$

Where $C_{F}$ is the total concentration of the analyte found, $C_{T}$ is a concentration of the analyte present in the tablet preparation; $C_{P}$ is a concentration of analyte (pure drug) added to tablets preparations. The results were recorded in table 4 . The high recovery values of the proposed methods indicated that the excipients did not interfere with the proposed methods indicating the high selectivity of the proposed methods.

Table 4: Results of recovery experiments by standard addition method for the determination of SOF and DAC in tablets dosage forms using the proposed methods

\begin{tabular}{|c|c|c|c|c|c|}
\hline Method & $\begin{array}{l}\text { Taken drug in } \\
\text { Tablet }(\mu \mathrm{g} / \mathrm{ml})\end{array}$ & $\begin{array}{l}\text { Pure drug added } \\
(\mu \mathrm{g} / \mathrm{ml})\end{array}$ & $\begin{array}{l}\text { Total found } \\
(\mu \mathrm{g} / \mathrm{ml})\end{array}$ & Recovery $^{a}(\%) \pm S D$ & Reported method \\
\hline Hopforhep tablets & SOF & & & & \\
\hline \multirow[t]{3}{*}{ IC } & 1.0 & 0.5 & 1.49 & $99.30 \pm 0.25$ & \\
\hline & 1.0 & 1.0 & 1.99 & $99.50 \pm 0.30$ & \\
\hline & 1.0 & 1.50 & 2.52 & $100.80 \pm 0.60$ & \\
\hline $\mathrm{X} \pm \mathrm{SD}^{\mathrm{a}}$ & & & & $99.87 \pm 0.81$ & $99.60 \pm 0.56[4]$ \\
\hline$t$-value $(2.57)^{\mathrm{b}}$ & & & & 0.61 & \\
\hline$F$-value $(5.05)^{\mathrm{b}}$ & & & & 2.09 & \\
\hline \multirow[t]{3}{*}{ ARS } & 1.0 & 0.5 & 1.485 & $99.00 \pm 0.40$ & \\
\hline & 1.0 & 1.0 & 2.008 & $100.40 \pm 0.50$ & \\
\hline & 1.0 & 1.50 & 2.485 & $99.30 \pm 0.70$ & \\
\hline $\mathrm{X} \pm \mathrm{SD}$ a & & & & $99.57 \pm 0.74$ & \\
\hline$t$-value $(2.57)^{\mathrm{b}}$ & & & & 0.07 & \\
\hline$F$-value $(5.05)^{\mathrm{b}}$ & & & & 1.75 & \\
\hline Daclahepex tablets & DAC & & & & \\
\hline \multirow[t]{3}{*}{ IC } & 1.0 & 0.5 & 1.487 & $99.10 \pm 0.20$ & \\
\hline & 1.0 & 1.0 & 2.01 & $100.50 \pm 0.30$ & \\
\hline & 1.0 & 1.50 & 2.475 & $99.00 \pm 0.50$ & \\
\hline $\mathrm{X} \pm \mathrm{SD}$ a & & & & $99.53 \pm 0.84$ & $99.40 \pm 0.73[10]$ \\
\hline t-value $(2.57)^{\mathrm{b}}$ & & & & 0.26 & \\
\hline$F$-value $(5.05)^{\mathrm{b}}$ & & & & 1.32 & \\
\hline \multirow[t]{3}{*}{ ARS } & 1.0 & 0.5 & 1.502 & $100.10 \pm 0.40$ & \\
\hline & 1.0 & 1.0 & 2.012 & $100.60 \pm 0.60$ & \\
\hline & 1.0 & 1.50 & 2.483 & $99.30 \pm 0.80$ & \\
\hline $\mathrm{X} \pm \mathrm{SD}$ a & & & & $100.00 \pm 0.66$ & \\
\hline$t$-value $(2.57)^{\mathrm{b}}$ & & & & 1.36 & \\
\hline$F$-value $(5.05)^{\mathrm{b}}$ & & & & 1.22 & \\
\hline
\end{tabular}

${ }^{a}$ Average of six determinations. ${ }^{\mathrm{b} T h e o r e t i c a l ~ v a l u e s ~ o f ~} \mathrm{t}$ and $\mathrm{F}$ at confidence limit at $95 \%$ confidence level and five degrees of freedom ( $\mathrm{p}=0.05$ ).

\section{Analysis of the pharmaceutical preparations}

The proposed methods were applied to the determination of SOF in (Hopforhep tablets) and DAC in Daclahepex tablets. The results of recovery $\pm S D$ values of the proposed methods agree well with the label claim and also were in agreement with the results obtained by the reported methods for SOF [4] and DAC [10] and were statistically compared with those obtained using the reference 
methods. Statistical analysis of the results, using Student's t-test and the variance ratio F-test at $95 \%$ confidence level revealed no significant difference between the performance of the proposed and reference methods regarding the accuracy and precision, respectively (table 4)[38]. It is evident from these results that the proposed methods are applicable to the analysis of SOF and DAC in its dosage forms with comparable analytical performance.

\section{CONCLUSION}

A new, simple, rapid, useful and cost-effective spectrophotometric methods have been developed for determination of SOF and DAC in pure form and tablets using cerium (IV) as oxidizing agent and validated as per the current ICH guidelines. The present spectrophotometric methods are characterized by simplicity of operation, high selectivity, comparable sensitivity, low-cost instrument, they do not involve any critical experimental variable and are free from tedious and timeconsuming extraction steps and use of organic solvents unlike many of the previous methods reported for SOF and DAC. The proposed methods have some additional advantages involve less stringent control of experimental parameters such as the stability of the colored system, accuracy, reproducibility, time of analysis, temperature independence and cheaper chemicals. These advantages encourage the application of the proposed methods in routine quality control analysis of SOF and DAC in pure and dosage forms.

\section{FUNDING}

Nil

\section{AUTHORS CONTRIBUTIONS}

Prof. Dr. Muneir Zaky has generated the research idea and interpreted the data and helped to draft the manuscript. Prof. Dr. Atef Amer has suggested the research idea and participated in the design of the study. Mr. Basem El Gendy was prepared the solutions, carried out the experiments, interpreted the data and helped to draft the manuscript. Dr. Khaled El Gendy helped in check spelling, reducing the plagiarism, interpreting the data, reviewed the manuscript and submit the manuscript for publication.

\section{CONFLICTS OF INTERESTS}

The authors confirm that this article content has no conflict of interest.

\section{REFERENCES}

1. FDA Approves Sovaldi for chronic hepatitis C. FDA New Release. United States Food and Drug Administration; 2013.

2. Essential Medicines WHO Model List, 19th edition, April 2015 (PDF). World Health Organization; 2015.

3. Rezk MR, Bendas ER, Basalious EB, Karim IA. Development and validation of sensitive and rapid UPLC-MS/MS method for quantitative determination of daclatasvir in human plasma: application to a bioequivalence study. J Pharm Biomed Anal. 2016;128:61-6. doi: 10.1016/j.jpba.2016.05.016, PMID 27232152.

4. S Eldin A, M Azab S, Shalaby A, El-Maamly M. The development of a new validated HPLC and spectrophotometric methods for the simultaneous determination of daclatasvir and sofosbuvir: antiviral drugs. J Pharm Pharmacol Res. 2017;01(1):28-42. doi: $10.26502 /$ jppr.15530004.

5. Bandla J, Ganapaty S. Development and validation of stability indicating RP-HPLC method for the simultaneous estimation of sofosbuvir and daclatasvir dihydrochloride in bulk drug and pharmaceutical dosage form. Saudi J PharmSci. 2018;4:542-51.

6. Zaman B, Siddique F, Hassan W. RP-HPLC method for simultaneous determination of sofosbuvir and ledipasvirin tablet dosage form and its application to in vitro dissolution studies. Chromatographia. 2016;79(23-24):1605-13. doi: 10.1007/s10337-016-3179-9.

7. Nekkala K, J SK, J SK, J SK. Analytical method development and validation for the simultaneous estimation of sofosbuvir and velpatasvir drug product by reverse phase high performance liquid chromatography method. Asian J Pharm Clin Res. 2018;11(2):164-8. doi: 10.22159/ajpcr.2018.v11i2.22465.

8. Sumathi K, Thamizhvanan K, Vijayraj S. Development and validation of stability indicating RP-HPLC method for the estimation of daclatasvir in bulk and formulation. Pharm Lett. 2016;8:107-13
9. Ashok Chakravarthy V, Sailaja BBV. Method development and validation of assay and dissolution methods for the estimation of daclatasvir in tablet dosage forms by reverse phase HPLC. Eur J Pharm Res. 2016;3:356-64.

10. El Sheikh R, Hassan WS, Gouda AA, Kamal MM. A rapid stability-indicating HPLC method for determination of daclatasvir in pure form and tablets. Int J Pharm Sci Rev Res. 2018;51:98-103.

11. Nannetti G, Messa L, Celegato M, Pagni S, Basso M, Parisi SG, Palù G, Loregian A. Development and validation of a simple and robust HPLC method with UV detection for quantification of the hepatitis C virus inhibitor daclatasvir in human plasma. J Pharm Biomed Anal. 2017;134:275-81. doi: 10.1016/j.jpba.2016.11.032, PMID 27939848.

12. Chakravarthy VA, Sailaja BBV. Method development and validation of assay and dissolution methods for the estimation of daclatasvir in tablet dosage forms by reverse phase HPLC. Eur J Pharm Res. 2016;3:356-64.

13. Moustapha ME, El-Gamal RM, Belal FF. Two novel UPLC methods utilizing two different analytical columns and different detection approaches for the simultaneous analysis of velpatasvir and sofosbuvir: application to their co-formulated tablet. BMC Chem. 2019;13(1):118. doi: 10.1186/s13065-0190635-2, PMID 31583391.

14. Shaik JO, Muniappan M, Manikanta KA, Muralidaran K, Ramulu Y, Venkat R. Estimation of sofosbuvir with validated Ultra High Performance Liquid Chromatographic (UHPLC) method in its bulk and formulations. Pharm Sin. 2017;8:10-5.

15. Rezk MR, Basalious EB, Karim IA. Development of a sensitive UPLC-ESI-MS/MS method for quantification of sofosbuvir and its metabolite, GS-331007, in human plasma: application to a bioequivalence study. J Pharm Biomed Anal. 2015;114:97-104 doi: 10.1016/j.jpba.2015.05.006, PMID 26037157.

16. Chenwei P, Yongping C, Weilai C, Guangyao Z. Simultaneous determination of ledipasvir, sofosbuvir and its metabolite in rat plasma by UPLC-MS/MS and its application to a pharmacokinetic study. J Chromatogr B Anal Technol Biomed Life Scince. 2016;1008:255-9.

17. Ariaudo A, Favata F, De Nicolo A, Simiele M, Paglietti L, Boglione L, Cardellino CS, Carcieri C, Di Perri G, D'Avolio A. A UHPLCMS/MS method for the quantification of direct antiviral agents simeprevir, daclatasvir, ledipasvir, sofosbuvir/GS-331007, dasabuvir, ombitasvir and paritaprevir, together with ritonavir, in human plasma. J Pharm Biomed Anal. 2016;125:369-75. doi: 10.1016/j.jpba.2016.04.031. PMID 27131146.

18. Azab SM, Fekry AM. Electrochemical design of a new nanosensor based on cobalt nanoparticles, chitosan and MWCNT for the determination of daclatasvir: a hepatitis C antiviral drug. RSC Adv. 2017;7(2):1118-26. doi: 10.1039/C6RA25826C.

19. Eissa MS, Fayed AS, Hegazy MA, Kamel EB. Spectrophotometry analysis for simultaneous determination of the new antiviral drug combination: Daclatasvir/sofosbuvir in their pure form and pharmaceutical preparation. Res J Pharm Technol. 2020;13(12):5939-46. doi: 10.5958/0974-360X.2020.01037.9.

20. Vikas K, Sachin G, Omprakash B. Development, validation and stability study of UV spectrophotometric method for determination of daclatasvir in bulk and pharmaceutical dosage forms. Int J ChemTech Res. 2017;10:281-87.

21. Jeevana JB, Padmaja G. UV spectrophotometric method for estimation of new drug, daclatasvir dihydrochloride. Int Res J Pharm. 2016;7:1-3.

22. Chakravarthy VA, Bbv S, A PK. Method development and validation of ultraviolet-visible spectroscopic method for the estimation of hepatitis-c drugs - daclatasvir and sofosbuvir in active pharmaceutical ingredient form. Asian J Pharm Clin Res. 2016;9(9):61-6. doi: 10.22159/ajpcr.2016.v9s3.14616.

23. Kishore MS, Rambabu C. Development and validation of UV spectrophotometric method for the estimation of sofosbuvir and ledipasvir in combined pharmaceutical dosage forms. Int ] ChemTech Res. 2019;12(3):33-40. doi: 10.20902/IJCTR.2019.120305.

24. Rathod SM, Patel PU. Development and validation for simultaneous estimation of sofosbuvir and daclatasvir 
dihydrochloride in pharmaceutical dosage form by ratio derivative and dual wavelength methods. IJPQA. 2020;11:25-31.

25. Nasr ZA, Said NS, Abdel-Razeq SA. Uv spectrophotometric methods for determination of sofosbuvir in pure form and pharmaceutical dosage forms in presence of its alkaline degradate. Asian J Appl. Chem Res. 2020;5:12-25.

26. Shalaby A, El-Maamly M, Abdel-Gawad FM, Azab SM, Eldin AS. Spectrophotometric determination of daclatasvir dihydrochloride by ion-pair reaction with bromophenol blue, bromothymol blue and bromocresol green. Chem Res J 2017(2):163-73.

27. Abdellatef HE, El-Henawee MM, El-Sayed HM, Ayad MM. Spectrophotometric and spectrofluorimetric methods for analysis of acyclovir and acebutolol hydrochloride. Spectrochim Acta A Mol Biomol Spectrosc. 2006;65(3-4):997-9. doi: 10.1016/j.saa.2006.01.001, PMID 16914365.

28. Krebs A, Starczewska B, Puzanowska-Tarasiewicz H, Sledz J. Spectrophotometric determination of olanzapine by its oxidation with $N$-bromosuccinimide and cerium(IV) sulfate. Anal Sci. 2006;22(6):829-33. doi: 10.2116/analsci.22.829, PMID 16772680.

29. El-Didamony AM, Erfan EAH. Utilization of oxidation reactions for the spectrophotometric determination of captopril using brominating agents. Spectrochim Acta A Mol Biomol Spectrosc. 2010;75(3):1138-45. doi: 10.1016/j.saa.2009.12.075, PMID 20080436.

30. El Shiekh R, Amin AS, Hafez EM, Gouda AA. Spectrophotometric estimation of vardenafil $\mathrm{HCl}$ and tadalafil in pure forms and tablets using cerium(IV) ammonium sulphate. Pharm Lett. 2016;8:153-65.

31. El-Didamony AM, Hassan WS. Spectrophotometric and fluorimetric methods for determination of naltrexone in urine, serum and tablets by oxidation with cerium (IV). J Chil Chem Soc. 2012;57(4):1404-8. doi: 10.4067/S071797072012000400015

32. El Sheikh R, Hassan WS, Gouda AA, Al Owairdhi AA. Validated and sensitive spectrophotometric methods for estimation of rizatriptan benzoate in pharmaceutical formulations using cerium (IV) Sulphate. Res J Pharm Technol. 2019;12:2123-30.

33. El Sheikh R, Hassan WS, Gouda AA, El Gabry MM. Utility of cerium (IV) Ammonium sulphate as oxidizing agent for spectrophotometric assay of oxybutynin hydrochloride in pharmaceutical preparations. Int J Res Pharm Pharm Sci. 2018;3:9-16.

34. El Sheikh R, Hassan WS, Gouda AA, Abdel Fattah GM. Validated spectrophotometric methods for determination of donepezil hydrochloride in pharmaceutical formulations based on redox reaction with cerric(IV) ammonium sulphate. Int J Pharm Sci Rev Res. 2018;52:66-74.

35. El Sheikh R, Gouda AA, Sadek LA. New spectrophotometric method for determination of aripiprazole in pure form and pharmaceutical formulations using ceric (IV) Ammonium sulphate. Int J Res Pharm Pharm Sci. 2018;3:259-67.

36. Jeffery GH, Bassett J, Mendham J, Denney RC. Titrimetric analysis. In: Vogel's a textbook of quantitative inorganic analysis. 5th ed. London: ELBS; 1989. p. 308.

37. International Conference on Harmonisation of Technical Requirements for Registration of Pharmaceuticals for Human Use. Complementary Guideline on Methodology. ICH harmonised tripartite guideline, validation of analytical procedures: text and methodology. Vol. Q2. London; 2005.

38. Miller JN, Miller JC. Statistics and chemometrics for analytical chemistry. 5th ed. Englewood Cliffs: Prentice Hall; 2005. 